Article

\title{
Chemical analysis of the main metabolites of three spontaneous plants from the Saharan area (Algeria)
}

ImeneRadjai $^{1 *}$, BrahimBouchareb ${ }^{1}$, Pablo Velasco ${ }^{2}$ and Gahdab Chakali ${ }^{1}$

1 Laboratoire de protection des végétaux en milieux agricoles et naturels contre les déprédateurs des cultures dans les régions d'Alger et de Blida, Ecole Nationale Supérieure Agronomique ;EL Harrach, 16200,Alger, Algérie ;imerad50@gmail.com(I.R.);bouchareb.brahim@gmail.com(B.B);g.chakali@ensa.dz(G.C.)

2 Group of Genetics, Breeding and Biochemistry of Brassicas, MisiónBiológica de Galicia (MBG-CSIC), E-36080 Pontevedra, Spain; pvelasco@mbg.csic.es (P.V.)

* Correspondence: imerad50@gmail.com; +213671848610

Citation:Lastname, F.; Lastname, F.; Lastname, F. Title. Plants 2021, 10, x. https://doi.org/10.3390/xxxxx

\begin{abstract}
Spontaneous plants metabolites are more widespread for their properties and biological functions. Also, natural products have reminded diverse scientists to take a delight in their medical and insecticidal applications linked to the environmental. A variety of metabolites have a defensive function for the plants. Thus, three spontaneous plants: Caroxylon imbricatum, Tetraena alba and Cotula cinerea collected from two ecotypes and analyzed by two known conventional methods:Gas Chromatography-Mass Spectrometry GC QTOF(quadrupole time of flight )_MS and Liquid Chromatography-Mass spectrometry LCQTOF(quadrupole time of flight )_MS. The investigation conducted out on the identification and quantification of metabolites revealed the main metabolites which have biological activities as a part of an alternative to synthetic insecticides. The chemical study showed the presence of N-Butylbenzensulfonamide and Sulfoxycaprylicacid in the three plants. $\mathrm{N}$-Carboxy-methionineresidue, Butanoicacid and Valine were found in those of Cotula cinerea and Caroxylon imbricatum (Forssk.). Artomunoxanthentrione, Glycoaldehyde, Indoline, ,Benzensulfonamide and Oxoproline were detected in extracts of Caroxylon imbricatum (Forssk.) and Tetraena alba (L.f.) In addition, Pyrroline is the only compound common in Cotula cinerea and Tetraena alba (L.f.).
\end{abstract}

Keywords: spontaneous plants;metabolites; insecticidal; identification; quantification

\section{Introduction}

Plant metabolites role against pests has developed considerably in the research for an alternative defence. The properties and biological functions of various secondary metabolites, natural products, have prompted various researchers to take an interest in their medical and insecticidal applications related to the environmental context. A variety of metabolites have a defensive role for the plants. 
Currently, plant metabolomics are progressively applicable in agrochemistry and specially in biocontrol and development of alternative methods for crop protection.

Metabolomics are as well a tool for apprehension plant-microorganism interactions and for the identification of bioactive compounds elaborate in those interactions that could induce inventive biocontrol products [9].

In this context, some plant metabolites were evaluated against pea aphid (Acyrthosiphon pisum). When tested in dual choice bioassays, to evaluate their feeding deterrence and mortality effect on pea aphids, 1-hexadecanol, gliotoxin, cyclopaldic acid and seiridin produce a high feeding deterrence while aphid mortality was significant for 1-heptadecanol, cytochalasin A, 1-nonadecanol and gliotoxin. Moreover, the phytotoxicity estimation revealed low or perceptible plant damaged for cytochalasin $\mathrm{A}$, seiridin and 1-nonadecanol. These results showed seiridin can be used as an alternative to synthetic insecticides. Nevertheless, more studies are required in spite of evaluate its realistic application [2].

Many researchers have reported on the efficacy of plant extracts against insects, mainly those infesting stored products. Mallotus repandus leaves and stems extracts have insecticidal activity against Culex quinquefasciatus and Sitophilus Oryzae[1,7,13,18].

Pesticides produced from plants are generally pest-specific and are relatively harmless to organisms. They are also biodegradable and do not pose a risk for the environment. Natural products generally inhibit the development and behaviour of insects.Additionally, they cause early moulting and alter regulatory hormones, consequently insect malformations, sterility, or death[8].

Some authors considered that the methanolic extracts of Artemisia absinthium, Juniperus phoenicea, and Tetraclinis articulate show favourable insecticidal and antifungal activities[7,11]. The test conducted by this investigation showed that the most toxic extract was that of A. Absinthium $(15.53 \mathrm{mg} / \mathrm{cm} 2)$, followed by that of $J$. phoenicea $(22.14 \mathrm{mg} / \mathrm{cm} 2)$, and T. Articulate $(24.05 \mathrm{mg} / \mathrm{cm} 2)$.All three extracts reduced the growth of Fusarium culmorum and F. graminearum. T. articulate was the most effective against the fungi. Results revealed the potential of plant methanolic extracts to control pests common to stored grains due to the presence of several phenolic acids, flavonoid glycosides, and flavonoid aglycones in plant extracts analyzed by UPLCPDA- MS.

inuloxins A, B and C and $\alpha$-costic acid, extracted from aerial parts of Dittrichia viscosa was evaluated against the cowpea seed beetle Callosobruchus maculatus. The results released that oviposition, adult emergence and sex ratio diversified according to the sex of the treated reproducing partner what indicate that compounds tested can have a property of male (or indirect female) chemosterilants bringing on low fecundity of untreated females that intercoursed with treated males [17].

[27] reported that Dittichia viscose compounds, in particular $\alpha$ - and $\gamma$-isomers of costic acid have a bio efficacy towards granary weevil Sitophilus granarius.

The results of Schinus molle, Mirabilis rotundifolia and Satureja calamintha essential oilseffect against Ryzopertha dominica which is the insect most frequently causing serious damages to stored products showed that the essential oil of $M$. rotundifolia has a 
significant insecticidal effect, comparably the essential oil of S. Calamintha and S. molle. The repulsive effect results of the oils tested showed that the three essential oils have a remarkable repelling effect[26].

Researches have been performed in various regions of North Africa on the importance and activity of these three Saharan plants metabolites which evolve on saline soils with difficult conditions, characterized by very pronounced drought; whose precipitations does not exceed $20 \mathrm{~mm} /$ year. According to inspections conducted in their environment, these spontaneous plants are used in traditional medicine [25]. Moreover,[4 , 5, $15,19,20,22]$ are interested in some biological activities among these insecticidal, acaricidal, antibacterial and antioxidant.

About classification and nomenclature, Cotula cinerea(Syn. Brocchia cinerea(Del) Vis), belonging to the family "Asteraceae", Tetraena alba (L.f.) Beier\& Thulin(formerly Zygophyllum album)Caroxylon imbricatum (Forssk.) Akhani \& Roalson (previously Salsola foetida) which had changed family from Salsolaceae to Amaranthaceae [14].

The present study was proposed to provide a qualitative and quantitative analysis of metabolites present in the three plants: Caroxylon imbricatum (Forssk.), Tetraena alba (L.f.) and Cotula cinerea using Gas Chromatography-Mass Spectrometry QTOF and Liquid Chromatography-Mass Spectrometry QTOF. Here, the investigation focused on the chemical analysis of extracts in order to discover new bioactive molecules and the development of effective biopesticides. The purpose which is to assured protection plants against many pests and protect consumer health from insecticide residues.

\section{Results}

\subsection{Identification of compounds by GC-MS-QTOF}

The results of the GC-MS analysis showed the presence of a substantial diversity of 16,000 metabolites. Some compounds for each plant were retained for identification(the most abundant chemical components were chosen).The constituents identified are shown in the tables 1 to 3.

Table 1.Chemical composition of Cotula cinerea analysed by GC-MS-QTOF

\begin{tabular}{lllll}
\hline RT & $\mathbf{m} / \mathbf{z}$ meas & Formula & MsMs & Compoud \\
\hline 2.08 & 141.00 & C3H8O2S2 & Yes & Ethylmethanethiosulfonate \\
2.67 & 90.06 & C9H25N5O2S & No & Unkonown \\
2.76 & 103.07 & C5H10O2 & No & Valericacid \\
7.39 & 371.10 & C16H22N2O4S2 & Yes & Unkonown \\
9.3 & 429.09 & C26H20O7 & No & Unkonown \\
13.92 & 371.10 & C27H14O2 & No & Unkonown \\
2.17 & 158.03 & C6H9NO3S & Yes & N-Carboxy-methionineresidue \\
2.17 & 214.09 & C10H15NO2S & Yes & N-Butylbenzenesulfonamide \\
2.6 & 89.06 & C4H8O2 & No & Butanoicacid \\
2.64 & 61.03 & C2H4O2 & No & Glycoaldehyde \\
3.38 & 214.09 & C10H15NO2S & Yes & N-Butylbenzenesulfonamide \\
5.62 & 223.06 & C8H16O6S & Yes & Sulfoxycaprylicacid \\
7.16 & 115.07 & C6H12O3 & No & Hydroxyhexanoicacid \\
7.74 & 153.12 & C10H16O & No & Perilylalcohol \\
\hline
\end{tabular}




\begin{tabular}{llll}
\hline 11.65 & 519.14 & C18H48OS8 & Unkonown \\
\hline
\end{tabular}

RT: retention time. $\mathrm{m} / \mathrm{z}$ meas: mass divided by charge number. Ms Ms : tandem mas spectrometry.

Table 2. Chemical composition of Caroxylon imbricatum (Forssk.) analysed by GC-MS-QTOF

\begin{tabular}{lllll}
\hline $\mathbf{R T}$ & $\mathbf{m} / \mathbf{z}$ & Formula & MsMs & Compound \\
& meas & & & \\
\hline 2.76 & 103.07 & C5H10O2 & No & Valeric acid \\
7.39 & 355.07 & C26H10O2 & No & Unkonown \\
7.39 & 371.10 & C27H14O2 & Yes & Unkonown \\
9.3 & 445.12 & C26H20O7 & No & Artomunoxanthentrione \\
9.3 & 429.09 & C14H36S7 & No & Unkonown \\
13.92 & 371.10 & C27H14O2 & No & Unkonown \\
2.17 & 158.03 & C6H9NO3S & Yes & N-Carboxy-methionine residue \\
2.6 & 89.06 & C4H8O2 & No & Butanoic acid \\
2.64 & 61.03 & C2H4O2 & No & Glycoaldehyde \\
5.57 & 225.05 & C14H8O3 & No & Hydroxyanthraquinone \\
5.62 & 223.06 & C8H16O6S & Yes & Sulfoxycaprylicacid \\
7.00 & 299.06 & C20H10O3 & No & Unknown \\
11.65 & 519.14 & C18H48OS8 & & Unknown \\
11.65 & 503.11 & C26H30O2S4 & Yes & 3-[[4-[(2-hydroxy-3 \\
& & & & phenylsulfanylpropyl)sulfanylmethyl] \\
& & & & phenyl]methylsulfanyl]-2-phenylsulfanylpropa \\
& & & & nol \\
13.36 & 593.16 & C18H50N4O2S8 & No & Unkonown \\
16.03 & 371.10 & C27H16O3 & Yes & Unkonown \\
\hline
\end{tabular}

RT: retention time. m/z meas: mass divided by charge number. Ms Ms: tandem mas spectrometry.

Table 3. Chemical composition of Tetraena alba (L.f.) analysed by GC-MS-QTOF

\begin{tabular}{lllll}
\hline RT & $\mathbf{m} / \mathbf{z}$ meas. & Formula & MsMs & Compound \\
\hline 2.67 & 90.06 & C9H25N5O2S & No & Unkonown \\
2.76 & 103.07 & C5H10O2 & No & Valericacid Acides gras alphatiques \\
6.7 & 223.06 & C10H10N2O4 & No & 6,7-Dimethoxyquinazoline-2,4(1H,3H)-dione \\
7.39 & 355.07 & C26H10O2 & No & Unkonown \\
7.39 & 371.10 & C27H14O2 & Yes & Unkonown \\
8.15 & 223.06 & C6H14N4S2 & No & Unkonown \\
9.3 & 445.12 & C26H20O7 & No & Artomunoxanthentrione \\
9.3 & 429.09 & C26H20O7 & No & Unkonown \\
2.17 & 214.09 & C10H15NO2S & Yes & N-Butylbenzenesulfonamide \\
2.64 & 61.03 & $\mathrm{C} 2 \mathrm{H} 4 \mathrm{O} 2$ & No & Glycoaldehyde \\
2.76 & 61.03 & $\mathrm{C} 2 \mathrm{H} 4 \mathrm{O} 2$ & No & Glycoaldehyde \\
3.38 & 214.09 & $\mathrm{C} 10 \mathrm{H} 15 \mathrm{NO} 2 \mathrm{~S}$ & Yes & N-Butylbenzenesulfonamide \\
4.87 & 149.04 & $\mathrm{C} 6 \mathrm{H} 6 \mathrm{~N} 4 \mathrm{O} 2$ & No & Methylxanthine \\
5.62 & 223.06 & $\mathrm{C} 8 \mathrm{H} 16 \mathrm{O} 6 \mathrm{~S}$ & Yes & Sulfoxycaprylicacid \\
7 & 299.06 & $\mathrm{C} 20 \mathrm{H} 10 \mathrm{O} 3$ & No & Unkonown \\
\hline
\end{tabular}




\begin{tabular}{lllll}
\hline 8.49 & 355.07 & $\mathrm{C} 26 \mathrm{H} 12 \mathrm{O} 3$ & No & Unkonown \\
13.36 & 593.16 & $\mathrm{C} 18 \mathrm{H} 50 \mathrm{~N} 4 \mathrm{O} 2 \mathrm{~S} 8$ & No & Unkonown \\
\hline
\end{tabular}

RT: retention time. $\mathrm{m} / \mathrm{z}$ meas: mass divided by charge number. Ms Ms : tandem mas spectrometry.

\subsection{Identification of compoundsby LC-MS-QTOF:}

The results of LC-MS analysis are representing in the tables 4 to 6 .

Table 4.Chemical composition of Cotula cinerea analysed by LC-MS-QTOF

\begin{tabular}{llll}
\hline RT & m/z meas. & Formula & Compound \\
\hline 0.53 & 23.60 & C10H15NO2S & N-Butylbenzensulfonamide \\
0.95 & 11.80 & C5H11NO2 & Valine \\
0.99 & 11.60 & C5H9NO2 & Proline \\
0.99 & 7.00 & C4H7N & Pyrroline \\
1.07 & 13.00 & C6H11NO2 & Pipecolicacid \\
17.98 & 36.42 & C21H25N5O & Unkonown \\
19.96 & 28.70 & C15H10O6 & 7-Hydroxy-2_-methoxyflavone \\
20.1 & 23.11 & C15H20O3 & Pechueloic acid \\
21.74 & 23.11 & C15H20O3 & Same. Could be an isomer or other compound \\
22.68 & 23.02 & C14H31NO & N,N-DimethyldodecylamineN-oxide \\
27.2 & 30.92 & C17H26N4 & Unkonown \\
27.21 & 11.11 & C8H14 & Unkonown \\
27.21 & 19.91 & C12H22O2 & Dodecalactone \\
27.34 & 29.72 & C16H34O3 & Unkonown \\
29.59 & 59.32 & C34H36N6O4 & Unknown \\
29.71 & 23.60 & C8H9N7S & Unkonown \\
30.01 & 47.73 & C26H54N4S & Unkonown \\
31.16 & 14.90 & C8H6O4 & Unkonown \\
31.16 & 11.31 & C8H16 & Octene \\
\hline
\end{tabular}

RT: retention time. $\mathrm{m} / \mathrm{z}$ meas: mass divided by charge number.

Table 5.Chemical composition of Caroxylon imbricatum (Forssk.) analysed by LC-MS-QTOF

\begin{tabular}{llll}
\hline RT & $\mathbf{m} / \mathbf{z}$ meas. & Formula & Compound \\
\hline 3.67 & 12.00 & C8H9N & Indoline \\
0.53 & 23.60 & C10H15NO2S & N-Butylbenzensulfonamide \\
0.67 & 14.10 & C6H4O2S & Unkonown \\
0.65 & 15.80 & C6H7NO2S & Benzensulfonamide \\
0.77 & 23.90 & C5H11N4O3PS & Unkonown \\
0.83 & 23.60 & C10H15NO2S & N-Butylbenzensulfonamide \\
0.93 & 21.70 & C5H10N6O5 & Unkonown \\
0.95 & 11.80 & C5H11NO2 & Valine \\
1.54 & 13.00 & C5H7NO3 & Oxoproline \\
19.27 & 46.93 & C31H40N4 & Unkonown \\
27.2 & 30.92 & C17H26N4 & Unkonown \\
27.21 & 11.11 & C8H14 & Unkonown \\
\hline
\end{tabular}




\begin{tabular}{llll}
\hline 27.34 & 29.72 & $\mathrm{C} 16 \mathrm{H} 34 \mathrm{O} 3$ & Unkonown \\
29.71 & 23.60 & $\mathrm{C} 8 \mathrm{H} 9 \mathrm{~N} 7 \mathrm{~S}$ & Unkonown \\
30.01 & 47.73 & $\mathrm{C} 26 \mathrm{H} 54 \mathrm{~N} 4 \mathrm{~S}$ & Unkonown \\
31.16 & 14.90 & $\mathrm{C} 8 \mathrm{H} 6 \mathrm{O} 4$ & Unkonown \\
31.16 & 11.31 & $\mathrm{C} 8 \mathrm{H} 16$ & Unkonown \\
\hline
\end{tabular}

RT: retention time. $\mathrm{m} / \mathrm{z}$ meas: mass divided by charge number.

Table 6.Chemical composition of Tetraena alba (L.f.) analysed by LC-MS-QTOF

\begin{tabular}{llll}
\hline RT & $\mathbf{m} / \mathbf{z}$ meas. & Formula & Compound \\
\hline 3.67 & 12.00 & C8H9N & Indoline \\
0.53 & 23.60 & C10H15NO2S & N-Butylbenzensulfonamide \\
0.66 & 21.40 & C10H15NO2S & N-Butylbenzensulfonamide \\
0.67 & 14.10 & C6H4O2S & Unkonown \\
0.65 & 15.80 & C6H7NO2S & Benzensulfonamide \\
0.83 & 23.60 & C10H15NO2S & Unkonown \\
0.99 & 7.00 & C4H7N & Pyrroline \\
1.54 & 13.00 & C5H7NO3 & Oxoproline \\
1.54 & 8.40 & C4H5NO & Methylisoxazole \\
27.2 & 30.92 & C17H26N4 & Unkonown \\
27.21 & 11.11 & C8H14 & Unkonown \\
27.34 & 29.72 & C16H34O3 & Unkonown \\
29.71 & 23.60 & C8H9N7S & Unkonown \\
30.01 & 47.73 & C26H54N4S & Unkonown \\
31.16 & 14.90 & C8H6O4 & Unkonown \\
31.16 & 11.31 & C8H16 & Unkonown \\
\hline
\end{tabular}

RT: retention time. $\mathrm{m} / \mathrm{z}$ meas: mass divided by charge number

\section{Discussion}

The compounds identified for Cotulacinereaare: Ethylmethanethiosulfonate, N-Butylbenzenesulfonamide, Glycoaldehyde, Hydroxyhexanoic acid, Perilyl alcohol, Proline, Pipecolic acid,7-Hydroxy-2_-methoxyflavone, Pechueloic acid, $\mathrm{N}, \mathrm{N}-$ Dimethyldodecylamine N-oxide, Dodecalactone and Octene.

In Caroxylon imbricatum(Forssk.) the following compounds identified are: Hydroxyanthraquinone, Sulfoxycaprylic acid and 3-[[4-[(2-hydroxy-3-phenylsulfanylpropyl)sulfanylmethyl] phenyl] methylsulfanyl] -2phenylsulfanylpropanol.

Valericacid,MethylxanthineandMethylisoxazole are identified fromTetraena alba (L.f.).

Those results reveal the presence of N-Butylbenzensulfonamide and Sulfoxy-caprylicacid in the three plants. N-Carboxy-methionineresidue, Butanoicacid and Valine were found in those of Cotula cinerea and. Caroxylon imbricatum (Forssk.) Artomunoxanthentrione, Glycoaldehyde, Indoline, ,Benzensulfonamide and 
Oxoprolinewere detected in extracts of Caroxylon imbricatum (Forssk.) and. Tetraena alba (L.f.) Pyrroline is the only compound common in Cotula cinerea and Tetraena alba (L.f.).

Many investigations have reported on identification of medicinal plants main constituents because of their interesting biological properties. Essential oil extracted from aerial parts of Cotula cinerea analyzed by GC-MS showed that (E)-citral, limoneneepoxidecis-, thymol methyl ether, carvacrol, trans-carveol,carvone and trans-piperitol were the considerable compounds [12].

Likewise,[10] noted the presence of 3-carène, thujone, santolinatriene and camphor from the oil obtained from a specimen collected in Oued Souf area.

The chiral flavanones analysis isolated from methanol extract of cotula cinerae aerial parts by TLC methods showed the presence of three compounds: Hesperidin, Hesperitin and Eriodoctyol [3].

The evaluation of antioxidant activity of Tetraena alba (L.f.) extracts showed that acid ascorbic have a considerable antioxidant effect [6]. Two phenolic compounds; Gallic acid and ascorbic acid were extracted from Tetraena alba (L.f.) floral honey, had a significatively antioxidant activity [24].

[21] reported the identification of three metabolites from whole plant of Caroxylon imbricatum(Forssk.):N-[2-(3,4-dihydroxyphenyl)-2-hydroxyethyl]-3-(4-methoxyphenyl) prop-2-enamide,N-[2-(3,4-dihydroxyphenyl)-2-hydroxyethyl]-3-(3,4-dimethoxyphenyl) prop-2-enamide and N-[2-(3-hydroxy-4-methoxyphenyl) -2- hydroxy ethyl] 3-(4-methoxy phenyl) -prop-2-enamide. Those compounds had an appreciable antioxidant activity and tyrosinase inhibition. These results are in accordance with many other studies. The aqueous extracts of Tetraena alba (L.f.) and Cotula cinerea collected from Oued Righ area have an acaricidal activity against themite of date palm Oligonychusa frasiaticus. These investigation results showed that Cotula cinerea extracts haven't an effect on the pest. Contrary, Tetraena alba have a high significant activity [22].

In addition, the study of Tetraena alba antifungal effect against the fungi of date palm released that the plant aqueous extracts and the powderhave an important reaction against the mycelia growth of date palm fungi (Alternaria sp., Fusarium sp., Phytophtorasp., Cladosporium sp., Aspergillus niger and Pinicilium sp.)[23].

Also, [4] tested the antioxidant effect of Tetraena alba ethanolic extract. The results considered that all extracts have strong reducing activity, while chloroform and ethyl acetate have large antiradical activity. The antioxidant activity in the fractions of Tetraena alba due to the polyphenol richness.

Similarly, in vitro antioxidant and antibacterial activity of Tetraena alba phenolic extracts and essential oils appeared a considerable effect by the methanolic extract of Tetraena alba[5].

Phytochemical content of Cotula cinerea analyzed to find principal components which may combine its use as a medicinal plant in the southeast of Morocco. All compounds exhibited very strong antioxidant capacities. The data show that the antioxidant capacities of the methanolic extracts of C. cinerea exhibit disease prevention efficacy, which is probably related to the high echinoids and flavonoids quantity [20]. 
[15] reported that Cotula cinerea extracted oil collected from south Morocco possessed a significant antibacterial, antifungal and anticandidal activities. However, the oil showed low antioxidant capacity. Concerning the insecticidal effect, the toxicity of essential oil against Tribolium castaneum was evaluated in the contact toxicity assay using adult insects Extracts of the tested Moroccan C.cinerea did not demonstrate any insecticidal activity. In the same study, the oil has moderate cytotoxic activity against both colorectal adenocarcinoma and hepatocellular carcinoma cell lines.Also, the essential oil composition of C.cinerea collected from Bechar in south area. The chemical composition was dominated by the presence of oxygenated monoterpenes followed by monoterpene hydrocarbons, oxygenated sesquiterpenes and sesquiterpene hydrocarbons $[12,15]$.

As well, [10] indicated that cotula cinerea essential oil analyzed by GCMS, constituted of 22 chemical compounds dominated by: 3-Carène, Thujone, Santolinatriene and Camphor during the flowering stage. While 21 chemical compoundswere obtained during the fruiting period with the dominance: Thujone, 3-Carène, Eucalyptol, Santolinatriene $(13.38 \%)$ and Camphor. According to the results, the chemical composition of essential oils have a correlation withintrinsic (genetic factor, harvest stage, state of the plant) andextrinsic factors (soil, climate, flora procession, insect pests and pollinators, human impact,ect..). Furthermore, the antibacterial effect of Cotula cinerea essential oil deduced:Enterococcus faecium, Escherichia coli, Morganella morganii, Proteus vulgaris, Staphylococcus aureus and Acinetobacter baumannii have a high sensitivity about the oil; even so, Pseudomonas aeruginosa has hard resistance with all concentrations.

In this regard, the extracts (hexane, ethyl acetate, and $n$-butanol) and the essential oil of Cotula cinerea which is widely used in the Moroccan traditional medicine. The cytotoxic effect was investigated against two cancer cell linesc, Vero and RD, using the colorimetric MTT assay.The results of this research indicated that Cotula cinerea essential oil and hexane extract have a significant cytotoxic effect against RD and Vero cell lines and could used as a source of strong anticancer products [16].

The antidiabetic, antidiarrheal, and antihypertensive activities of analyzed Tetraena alba essential oil collected from Douz area in Tunisia demonstrated for the first time the antidiabetic effect of essential from leaves which was observed by upgrading the hyperglycemia, hyperlipidemia,diarrhea, and hypertension a causal factor of arteriosclerosis which confirms the use of Tetraena alba oil in traditional medicine[25].

Similar observations have been made for [19]: the inhibitory effect of Tetraena alba essential oil leaves against key enzymes associated to diabetes and obesity. In addition, this oil presented adequate antibacterial activity especially against gram-positive bacteria. Furthermore, the study demonstrated a remarkable correlation between phenolic contents and amylase, antibacterial, pancreatic lipase inhibitory activities as well as their antioxidant activity. The investigation brings the medicinal use of Tetraena alba in the development of antioxidant, anti-diabetic and anti-obesity drugs.

\section{Materials and Methods}

\subsection{Biological material}


The choice of the plants to be tested is done according to their medicinal importance. Aerial parts of Tetraena alba and Cotulacinereawere collected in 2019 from the OuedSouf area located in southern Estand represented by dry weather. The third plant, Caroxylon imbricatum was assembled in august from Adrar area positioned in southern west of Algeria with hyper-dry weather. The table 7 shows the characteristics study sites. After confirmation of species identified, aerial parts of each plant were air-dried and then powdered by using electric grinder then stored away from humidity in bags of conservation.

Table 1. Characterisation of sampling sites

\begin{tabular}{|c|c|c|c|c|c|}
\hline Location & Geographical coordinates & $\begin{array}{l}\text { Mean annual } \\
\text { temperature }\end{array}$ & $\begin{array}{l}\text { Mean annual } \\
\text { precipitation }\end{array}$ & $\begin{array}{l}\text { Area } \\
\left(\mathrm{Km}^{2}\right)\end{array}$ & $\begin{array}{l}\text { Altitude } \\
(\mathrm{m})\end{array}$ \\
\hline Oued Souf & $33^{\circ} 21^{\prime} 21^{\prime \prime} \mathrm{N} 6^{\circ} 51^{\prime} 47^{\prime \prime} \mathrm{E}$ & 21 & 77 & 35706 & 80 \\
\hline Adrar & $27^{\circ} 52^{\prime} 27^{\prime \prime} \mathrm{N} 0^{\circ} 17^{\prime} 37^{\prime \prime} \mathrm{O}$ & 24 & 12 & 427300 & 276 \\
\hline
\end{tabular}

\subsection{Extraction technique}

The extraction was perfomed in the laboratory of Genetics, Breeding and Biochemistry Group of Brassicas, MisiónBiológica de Galicia (MBG-CSIC)( Pontevedra,Spain). For each extraction method we considered 3 samples of $100 \mathrm{mg}$ per plant.

\subsubsection{Gas Chromatography-Mass Spectrometry GC QTOF(Quadrupole Time of Flight )_MS}

Samples were prepared by adding $1 \mathrm{ml}$ of ethylacetate, placing them in Vortex during 15 seconds and putting them in the sonicate during 15 minutes. The material thus prepared is centrifuged for 10 minutes to separate the liquid from the solid. Samples were filtered using a $0.2 \mu \mathrm{m}$ WHATMAN filter.A dilution of $10 \mu \mathrm{l}$ of filtered sample and $990 \mu \mathrm{l}$ of ethylacetate was prepared.

Metabolites were analysed using a Gas Chromatograph coupled to a Quadrupole-Time of Flight Mass Spectrometer (GC-QTOF-MS) consisting of a Gas Chromatograph (7890B Agilent Technologies), QTOF Mass Spectrometer (7200 Agilent Technologies) and an autosampler (GC Sampler 120 Agilent Technologies). The column was an HP5-MS (30m×0.25mm inner diameter, $0.25 \mu \mathrm{m}$ film thickness) from Agilent Technologies.The GC-MS QTOF is used to separate volatile and semi volatile compounds. The separation of the mixture depends on the length and temperature of the column $\left(\mathrm{T}=290^{\circ} \mathrm{C}\right)$.

4.2.2. Liquid Chromatography-Mass Spectrometry LCQTOF(Quadrupole Time of Flight )_MS

The extraction method was modofied from Plant Metabolomics by Hardy and Hall, chapter 8,Ric de Vos, for Brassicaceae from Plant Metabolomics.. Chapter by Ilana Rogachev and Asaph Aharani. 


\subsubsection{Sample extraction solution}

Three products are utilised for this procedure: Methanol (MeOH) HPLC grade, Acetate Buffer: $2.3 \mathrm{~mL}$ acetic acid and 3.41g ammonium acetate in $1 \mathrm{~L}$ Milipore, Water the Buffer should have a $\mathrm{pH}$ of 4.8 , if not adjust with $0.1 \mathrm{Ml}$ or $0.1 \mathrm{M} \mathrm{NaOH}$ (Reagent grade or ACS grade) andExtraction Buffer: mix acetate buffer (25\%) with Methanol (75\%), e.g. mix $250 \mathrm{ml}$ with acetate buffer with $750 \mathrm{ml}$ methanol.

\subsubsection{Extraction process}

The considering solutions were prepared by dissolving $100 \mathrm{mg}$ of biological material into $1 \mathrm{~mL}$ extraction solution, shacked in the vortex for 10 seconds and in the sonicate for 5 minutes at $30 \mathrm{~Hz}$. Tubes were centrifuged for 10 minutes, solutions were Transferred into a new labelled Eppendorf tube. $1 \mathrm{~mL}$ extraction solution was added to the pellet of the 1st extraction, shacked for 10 seconds and in the sonicate during 5 minutes at $30 \mathrm{~Hz}$, centrifuge for 10 minutes at $20.000 \mathrm{~g}$. Then, the supernatant was combined with the one from the first extraction and centrifuged for 5 minutes.Afterwards $200 \mu \mathrm{L}$ of solution was transferred in a HPLC vial with $800 \mu \mathrm{L}$ of the extraction solution to obtain a dilution of $1 / 5$. Finally, the vials were transferred to the LC/MS for analysis.

The chromatographic apparatus composed of an LC Agilent Infinity System is equipped with an Infinity 1260 gradient pump, a 1260 HiPals automatic injector, a columnthermostat 1290, a photodiode array detector Infinity 1290,Accurate-Mass Quadrupole Time-of-Flight 6520 (QTOF-MS)Mass Spectrometer equipped with an electrospray ionization source, and a computer with Mass Hunter software for data acquisition andprocessing (Agilent Technologies).The LC-MS is used to separate soluble and untargeted compounds. It also use solvents $\mathrm{H} 2 \mathrm{O}$ and Acetonitril for create a gradient of polarity. $(95 \%$ water and $5 \%$ acetonitril). The measuring parameters of LC-MS QTOF are: a flow of $0,4 \mathrm{~mL} / \mathrm{min}$ and a pressure of $250 \mathrm{bar}$.

\subsection{Metabolites identification}

Metabolites were analysed by GC and LC with QTOF-MS detection. The parameters: retention time, molecular formula, $\mathrm{m} / \mathrm{z}$ experimental and calculated, $\mathrm{m} / \mathrm{z}$ of the principal fragments and error and Score were allowed the identification of these compounds. The data bases were considered for identification are Metaboscape from Bruker, Sirius, Metlinscripps and Knapsack metabolomics. Specific software for HPLC is Chromeleon Chromatography Data System.

\section{Conclusions}

The three spontaneous plants collected from desert are rich of metabolites which ones could be applied as a potential source to control pests of insects. Also, it appears that these compounds are cure for some disease and possesses several biological activities such as antifungal, antibacterial, antioxidant. Further investigation on the isolation and identification of biocompounds in the plan may lead to chemical entities with the potential for biocontrol strategy use. 


\begin{abstract}
Author Contributions: For research articles with several authors, a short paragraph specifying their individual contributions must be provided. The following statements should be used

“Conceptualization, I.Radjai.,G.Chakali.and B. Bouchareb.; methodology, I.Rdajai.,P.Velasco.; software, P.Velasco.,I.Radjai; validation, I.Radjai.,B.Bouchareb. and G.Chakali.; formal analysis,I.Radjai., P.Velasco.; investigation, I.Radjai.,B.Bouchareb. and G.Chakali.; resources, P.Velasco.; data curation, I.Radjai.,P.Velasco,.B.Bouchareb.; writing-original draft preparation, I.Radjai.; writing-review and editing,I.Radjai.,G.Chakali.; visualization, G.Chakali.; supervision, G.Chakali.; project administration, X.X.; funding acquisition, Y.Y. All authors have read and agreed to the published version of the manuscript."Please turn to the CRediT taxonomy for the term explanation. Authorship must be limited to those who have contributed substantially to the work reported.
\end{abstract}

Acknowledgments: The study was funded by the Ministry of High Education and Scientific Research, Ecole Nationale Supérieure Agronomique,Phd Program,Algeria. We would like to thank everyone who have provided a lot of help during the progress of this experiment. We thank Pablo Velasco (MBG-CSIC) for providing doctoral research collaboration.

Conflicts of Interest: The authors declare no conflicts of interest.

\title{
References
}

1. Akhtar,M.;Arshad,M.; Raza, A.B.M.; Chaudhary,M.I.; Iram,N.; Akhtar,N.; Mahmood,T. Repellent effects of certain plant extracts against rice weevil, Sitophilus oryzae L. (Coleoptera: Curculionidae). Int. J. Agric. Appl. Sci. 2013, 5(1), pp. 69-73.

2. Aznar-Fernández,T.; Cimmino,A.; Masi,M.; Rubiales,D. and Evidente,A. Antifeedant activity of long-chain alcohols, and fungal and plant metabolites against pea aphid (Acyrthosiphon pisum) as potential biocontrol strategy. Nat. Prod. Resea. 2018, 33 (17), pp.2471-2479, doi :org/10.1080/14786419.2018.1452013.

3. Belboukhari,N.;Cheriti,A.and Bouanini,M.Chiral separation of flavanones from cotula cinerea by TLC methods. PhytoChem. BioSub. J.2012, 6 (2), pp.2170-1768.

4. Belguidoum, M.; Dendougui,H.and Kendour,Z. In vitro antioxidant properties and phenolic contents of Zygophyllum albumL.from Algeria. J.Chemic.Pharma. Resear.2015, 7 (1), pp.510-514.

5. Belmimoun,A.; Meddah,B.; Meddah,A,T. and Sonnet,P. Antibacterial and antioxidant activities of the essential oils and phenolic extracts of Myrtus communis and Zygophyllum album from Algeria.J.Fund. Appli.scien.2016, 8(2), pp. 510-52, doi:org/10.4314/jfas.v8i2.22.

6. Benslama, A. and Harrar, A.(2016).Free radicals scavenging activity and reducing power of two Algerian Sahara medicinal plants extracts.Intern.J.Herb.Medic.2016, 4(6),pp. 158-161.

7. Benzi, V.; Stefanazzi, N.; Ferrero, A.A. Biological activity of essential oils from leaves and fruits of pepper tree (Schinus molle L.) to control rice weevil (Sitophilus oryzae L). Chil. J. Agric. Res. 2009, 69(2), pp.154-159 ,doi: 10.4067/ S0718-58392009000200004.

8. Bhatt,P.;Thodsare,N.and Srivastava,R,P. Toxicity of some bioactive medicinal plant extracts to Asian army worm, Spodoptera litura.J. Appli. Natur.Scien.2014, 6 (1), pp. 139-143.

9. Cedric, B.; Azucena, G,C. and Claire P,C. Plant metabolomics to the benefit of crop protection and growth stimulation. Adv. in Botl .Res.2020, ISSN 0065-2296, doi :org/10.1016/bs.abr.2020.11.002.

10. Chouikh ,A.; Mayache ,B. ;Maazi M, C. ;Hadef, Y. and Chefrour,A. Chemical composition and antimicrobial activity of essential oils in Xerophytic plant Cotula cinerea Del (Asteraceae) during two stages of development: flowering and fruiting.J.Appli. Pharmac. Scien.2015, 5 (03), pp. 029-034, doi: 10.7324/JAPS.2015.50306. 
11. Dane,Y. ;Mouhouche,F. ;Canela-Garayoa,R. and Delpino-Rius,A.Phytochemical Analysis of Methanolic Extracts of Artemisia absinthiumL. 1753 (Asteraceae), Juniperus phoeniceaL., and Tetraclinis articulata(Vahl) Mast, 1892 (Cupressaceae) and evaluation of their biological activity for stored grain protection. Arab.J.Scien. Engin.2015, doi: 10.1007/s13369-015-1977-2.

12. Djellouli,M.; Benmehdi,H.; Mammeri,S.;Moussaoui,A.; Ziane,L.;Hamidi,N. Chemical constituents in the essential oil of the endemic plant Cotula cinerea (Del.) from the southwest of Algeria. Asi.Pac.J.Trop. Biomed.2015, 5(10), pp.870-873, doi:org/10.1016/j.apjtb.2015.06.007.

13. Djouahri, A.; Saka, B.; Boudarene, L.; Benseradj, F.; Aberrane, S.; Aitmoussa, S.; Chelghoum, C.; Lamari, L.; Sabaou, N.; Baaliouamer, A. In vitro synergistic/antagonistic antibacterial and anti-inflammatory effect of various extracts/essential oil from cones of Tetraclinis articulata (Vahl) masters with antibiotic and anti-inflammatory agents. Ind. Crops Prod. 2014,56, pp.60-66 , doi:10.1016/j.indcrop.2014.02.035

14. DOBIGNARD,A. and CHATELAIN,C.Index synonymique et bibliographique de la flore d'Afrique du Nord, Volume. 2 :Dicotyledonae, Acanthaceae à Asteraceae ;C.J.B.G ; Editeur des conservatoire et Jardin botanique ville de Genève , Genève, 2011.

15. Fathy ,KF.; Dekinash,MF.; Beltagy, AM.; Moataz,Bellah, EM. and Khattab, AR.(2017).Chemical Composition and Biological Activity of Essential Oil from Cotula cinerea(Del.) Growing Wildly in the Middle East: A Short Review.Intern.J.Pharma.Chin. Medic.2017, 1(1), 000103.

16. Guaouguaou,F,E. ; Ahl Bebaha, M, A.; Taghzouti,K.; Bouyahya, A.; Bakri,Y.; Dakka,N. And Es-Safi,N. Cytotoxicological Investigation of the Essential Oil and the Extracts of Cotula cinerea and Salvia verbenaca from Morocco.BioM. Resear. Intern.2018, ID 7163961, 5 p, doi: 10.1155/2018/7163961.

17. Gueribis,F.;Zermane,N.;Khalfi-Habess,O .Siafa,A. ;Cimmino,A. ;Boari,A. and Evidente,A.Bioefficacy of compounds from Dittrichia viscosa(Asteraceae) as protectant of chickpea seeds against the cowpea seed beetle Callosobruchus maculatus (Coleoptera: Chrysomelidae).J.Plant. Dis.Prot.2019, doi: org/10.1007/s41348-019-00240-w.

18. Hasan,Md,R.; Uddin,N.; Hasan, Md,M.; Hossain,Md,M. ; Kamal,M,M. ; Fatema,K.; Mazumder,H, M, L, R .; Bashar, K. And Rana, Md. S. Larvicidal and insecticidal effects of different extracts of mallotus repandus(willd.) Muell.- arg. Leaf and stem against culex quinquefasciatus say (diptera: culicidae) and sitophilus oryzae linn. (coleoptera: curculionidae).Intern.J.Pharm.2015, 5(1),pp.127-133.

19. Kchaou, M.;Ben Salah,H.; Mnafgui,K.;Abdennabi, R.; Gharsallah,N.; Elfeki, A.; Damak, M. ; and Allouche,N. Chemical Composition and Biological Activities of Zygophyllum album (L.) Essential Oil from Tunisia.J.Agri. Sc.Tech.2016,18,pp. 1499-1510.

20. Khallouki,F.; Sellam,K.; Koyun,R.; Ricarte,I.;Alem,C. ; Elrhaffari,L. and W. Owen,R. Phytoconstituents and in vitro Evaluation of Antioxidant Capacities of Cotula Cinerea(Morocco) Methanol Extracts.Recor.Nat.Prod.2015, 9(4) , pp.572-575.

21. Khan,K,M.; Maharvi,G,M.; Abbaskhan, A.; Hayat,S.; Khan,M,T,H.;Makhmoor,T.; Choudhary,M,I.;Shaheen,F. and Atta,U,R.. Three Tyrosinase Inhibitors and Antioxidant Compounds from Salsola foetida.Helv.Chim. Acta.2003, 86,doi : 10.1002/hlca.200390045.

22. Lakhdari, W .;Dehliz, A.;Acheuk, F.;Soud, A.;Hammi, H.; Mlik, R. and Doumandji-Mitiche, B.Acaricidal Activity of Aqueous Extracts against the mite of date palm Oligonychus afrasiaticus Meg (Acari: Tetranychidae).J.Med.Plant.Stud.2015,3(6),pp. 113-117. 
23. Lakhdari,W.; Dehliz,A.; Acheuk,F.; Mlik,R.;Hammi,H.; Maatallah, S. and Doumandji-Mitiche,B. Biological control assay against date palm diseases by using an aqueous extract of Zygophyllum album in the southeast of Algeria. Intern.J.Herb.Med.2016, 4(4),pp.31-37.

24. Mesbahi, M, A.; Ouahrani,M, R.; Rebiai, A.; Amara, D, G.; and Chouikh ,A. Characterization of Zygophyllum album L Monofloral Honey from El-Oued, Algeria.Cur. Nutr. Food. Sci.2019, 15(5), pp.476-483, doi: 10.2174/1573401314666180223135430.

25. Mnafgui,K.; Kchaou,M.; Ben Salah,H.; Hajji,R.; Khabbabi,G. ; Elfeki,A.;Allouche,N. and Gharsallah,N. Essential oil of Zygophyllum album inhibits key-digestive enzymes related to diabetes and hypertension and attenuates symptoms of diarrhea in alloxan-induced diabetic rats.Pharm. Biol.2015, pp.1-8, doi: org/10.3109/13880209.2015.1075049.

26. Righi,K.; Righi,F,A.; Boubkeur,A.; Boungab,K.; Elouissi,A. and Djendara,A,C. Toxicity and repellency of three Algerian medicinal plants against pests of stored product: Ryzopertha dominica (Fabricius) (Coleoptera: Bostrichidae).Ban.J.Biotech.2017, doi: 10.7904/2068-4738-IX(17)-50.

27. Rotundo,G.; Paventi, G.; Barberio ,A.; De Cristofaro, A.; Notardonato, I.; Russo M,V. and Germinara, G,S. (2019). Biological activity of Dittrichiaviscosa(L.) Greuter extracts against adult Sitophilus granaries (L.) (Coleoptera, Curculionidae) and identification of active compounds. Sci. Rep.2019,9,6429,doi:org/10.1038/s4159 8-019- 42886 -4. 